\title{
STUDI KOMPARASI PEMODELAN 1-D (SATU DIMENSI) DAN 2-D (DUA DIMENSI) DALAM MEMODELKAN BANJIR DAS CITARUM HULU
}

\author{
Riza Inanda Siregar ${ }^{1}$, Ivan Indrawan ${ }^{2}$ \\ 1,2Dosen Pengajar Departemen Teknik Sipil, Fakultas Teknik, USU, Medan \\ Surel : rizawaloed@yahoo.com,ivanindrawan76@gmail.com \\ Diterima : 21 November 2017; Disetujui : 28 November 2017
}

\begin{abstract}
ABSTRAK
Pengelolaan Daerah Aliran Sungai (DAS) yang tidak baik akan menimbulkan kerusakan. Salah satu indikasi bahwa suatu DAS mengalami kerusakan adalah terjadinya banjir. Pada saat kondisi jumlah air sungai melebihi kapasitasnya atau menjadi terlalu banyak maka terjadi banjir yang diakibatkan oleh luapan sungai. Faktor dari peristiwa alami seperti intensitas curah hujan yang tinggi merupakan penyebab terjadinya banjir, ditambah lagi dengan faktor aktifitas manusia. Salah satu cara untuk mengantisipasi bencana banjir adalah dengan memprediksi terjadinya banjir tersebut. Studi ini bertujuan untuk menganalisis perbedaan hasil yang diperoleh pada pemodelan 1-D dan 2-D terkait akurasi hasil untuk analisis lanjutnya. Keterbatasan data yang diperoleh dan ketepatan pemilihan metode pemodelan banjir akan mengurangi keakuratan hasil pemodelan dalam memprediksi banjir. Secara garis besar metode pemodelan banjir terdiri dari dua bagian yaitu pemodelan hidrologi (hydrology modeling) dan pemodelan hidrolika (hydraulic modeling). Pemodelan hidrologi pada daerah studi yaitu DAS Citarum Hulu, Jawa Barat menggunakan hidrograf metode SCS dan Snyder dengan bantuan software HEC-HMS, sedangkan pemodelan hidrolika menggunakan bantuan software HECRAS. Hasil yang diperoleh akan dilakukan kalibrasi dan verifikasi. Pemodelan dengan HEC-RAS 5.03 dianalisis untuk model 1-D dan 2-D, kemudian kedua data komparasikan untuk menganalisis perbedaan atau rentang hasil yang diperoleh terkait pemilihan metode pada DAS yang lain.
\end{abstract}

Kata Kunci : Banjir, Citarum, Flood Modeller, Pemodelan, Sungai Deli

\begin{abstract}
Management of Watersheds (DAS) will cause damage if one indication that a watershed is damaged is the occurrence of floods. When the condition of the river water exceeds its capacity or becomes too much, there will be flood caused by the river flood. Factors of natural events such as high rainfall intensity is the cause of flooding, coupled with the factor of human activity. One way to anticipate flood disaster is to predict the occurrence of the flood. This study aims to analyze the differences in results obtained in 1-D and 2-D modeling on yield accuracy for further analysis. Limitations of the data obtained and the accuracy of selection of flood modeling methods will reduce the accuracy of the modeling results in predicting flooding. The method consists of two parts, hydrology modeling and hydraulic modeling. Hydrology modeling in the study area is upper Citarum Watershed, West Java using hydrograph of SCS and Snyder method with HEC-HMS software, while hydraulic modeling using HEC-RAS software. The results obtained will be calibration and verification. Modeling with HEC-RAS 5.03 was analyzed for 1-D and 2-D models, then the two comparative data to analyze the difference or range of results obtained related to the selection of methods in other watersheds
\end{abstract}

Keywords: Citarum, Deli River, Flood, Modelling

\section{Pendahuluan}

Banjir merupakan suatu peristiwa yang terjadi ketika aliran air yang berlebihan merendam suatu daratan. Banjir juga bisa terjadi pada Daerah Aliran Sungai (DAS), ketika aliran air melebihi kapasitas maksimum sungai maka air akan meluap sehingga terjadi banjir. Faktor dari peristiwa alami seperti intensitas curah hujan yang tinggi merupakan penyebab terjadinya banjir ditambah lagi 
dengan faktor aktifitas manusia. Selain itu faktor pengelolaan DAS yang kurang baik dan tidak tepat menjadi salah satu faktor yang sering terjadi di wilayah sungai yang ada di Indonesia. Akibat yang ditimbulkan banjir dapat menyebabkan kerusakan dan kerugian masyarakat dengan tingkatan yang berbedabeda. Besarnya tingkat kerusakan dan kerugian tersebut dapat diminimalisir apabila banjir yang terjadi dapat dipredikasi. Salah satu cara memperkecil resiko bencana banjir adalah dengan memperkirakan dimana suatu daerah akan berpotensi terlanda banjir. Kesesuaian metode dalam memprediksi banjir berpengaruh terhadap hasil analisis pengendalian banjir.

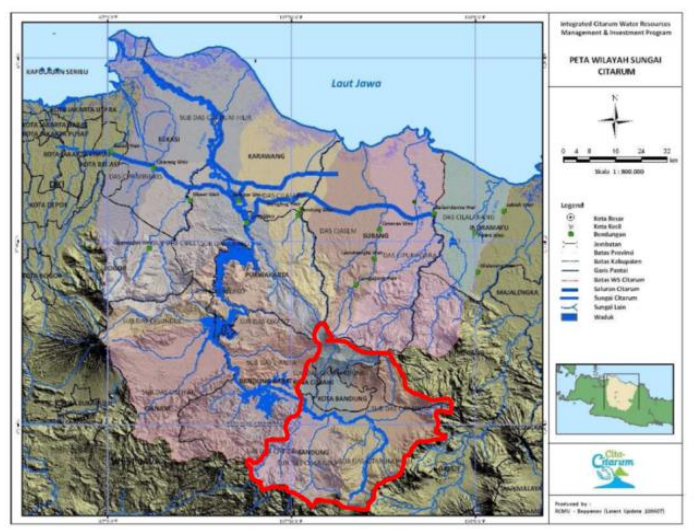

Gambar 1. Daerah Aliran Sungai Citarum (Sumber: Dokumen BBWS Citarum)

Pengembangan model prediksi banjir sudah banyak dilakukan oleh peneliti-peneliti di Indonesia. Namun, tingkat kerugian dan kerusakan masih besar, hal tersebut dapat diakibatkan oleh penentuan parameter dalam model prediksi banjir belum sesuai dengan kondisi atau karakteristik daerah banjir. Beberapa model prediksi banjir yang biasa digunakan antara lain pemodelan hidrologi (hydrology modeling) dan pemodelan hidrolika (hydraulic modeling). Pemodelan hidrolika dapat diinterpretasikan ke dalam pemodelan 1-D (one dimensional modelling) dengan pemodelan 2-D (two dimensional modelling). Kedua pemodelan tersebut memiliki input data yang berbeda dengan tujuan yang sama dalam memodelkan banjir, sehingga jika telah di kalibrasi dan verifikasi dengan debit pengukurannya tentu mendapatkan pemodelan dengan analisis yang berbeda. Studi ini bertujuan untuk menganalisis perbedaan hasil yang diperoleh pada pemodelan 1-D dan 2-D terkait akurasi hasil untuk analisis lanjutnya.
DAS Citarum Hulu didefinisikan sebagai satu wilayah yang berfungsi menampung, menyimpan dan mengalirkan air di hulu Waduk Saguling (Curug Jompong) dengan luas total DAS $1.771 \mathrm{~km}^{2}$. DAS Citarum hulu mengalir melalui daerah selatan Kabupaten Bandung (melewati Kecamatan Rancaekek, Sapan, Baleendah dan Dayeuh Kolot) hingga Waduk Saguling. DAS Citarum Hulu secara geografis terbentang pada $6^{\circ} 43^{\prime} 21,8^{\prime \prime}$ $7^{\circ} 19^{\prime} 38,1^{\prime \prime}$ LS dan $107^{\circ} 32^{\prime} 2^{\prime \prime}-107^{\circ} 53^{\prime} 51,6^{\prime \prime}$ BT. DAS Citarum Hulu secara administratif melewati beberapa kota dan kabupaten, seperti Kabupaten Bandung, Sumedang, Kota Bandung dan Kota Cimahi. Berdasarkan karakteristik hidrologisnya, dibedakan atas subdas pada Cekungan Bandung Utara dan Bandung Selatan yang masing-masing memiliki keragaman curah hujan dan waktu konsentrasi berbeda.

\section{Kajian Pustaka}

\subsection{Pemodelan 1D dan 2D}

Pemodelan 1 dimensi adalah pemodelan yang memiliki satu arah aliran yaitu arah aliran sepanjang alur utama. Sedangkan Pemodelan 2 dimensi adalah pemodelan yang memiliki dua arah aliran yaitu arah aliran sepanjang alur utama dan arah aliran disekitar aliran. Pemodelan tersebut merupakan suatu pemodelan hidraulik akan menganalisis hitungan hidraulik yang pada dasarnya adalah mencari kedalaman dan kecepatan aliran di sepanjang alur yang merupakan hasil dari debit yang di input sebagai syarat batas. Pada pemodelan terdapat beberapa komponen dalam pemodelan 1 dimensi yaitu menentukan profil muka air pada aliran permanen (steady flow), simulasi pada aliran tak permanen (unsteady flow), menghitung sediment transport, dan menganalisis kualitas air. Komponenkomponen tersebut menggunakan data geometri yang sama, routine hidrolika yang sama, dan beberapa fitur desain hidraulik yang dapat dilakukan setelah mengetahui profil muka air.

\subsection{Konsep Hidrograf Banjir}

Respons suatu Daerah Aliran Sungai (DAS) terhadap hujan adalah limpasan permukaan (runoff). Hujan merupakan faktor utama yang menyebabkan banjir. Karakteristik hujan yang menyebabkan banjir adalah intensitas hujan yang tinggi dan durasi hujan yang lama. Ketika suatu DAS merespons hujan menjadi limpasan langsung maka karakteristik debit tersebut sangat bergantung pada konstanta dan variabel 


\section{Studi Komparasi Pemodelan 1-D (Satu Dimensi) Dan 2-D (Dua Dimensi) Dalam Memodelkan Banjir Das Citarum Hulu}

DAS. Salah satu konstanta yang mempengaruhinya adalah koefisien guna lahan. Gambar berikut merupakan konsep hidrograf banjir

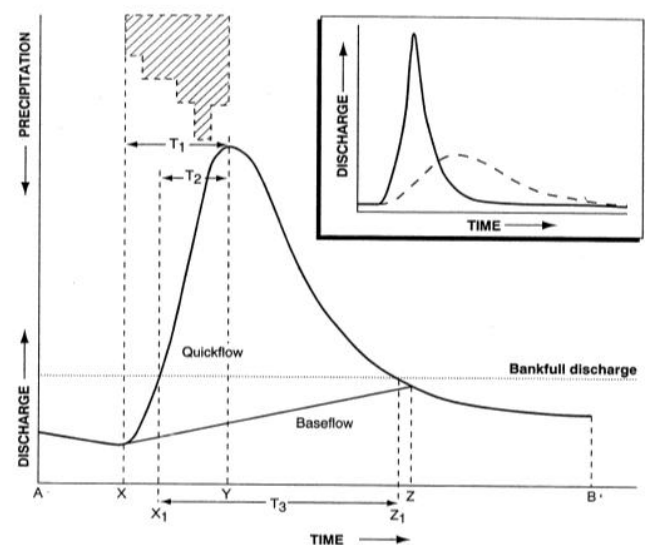

Gambar 2. Konsep hidrograf banjir pada DAS (Sumber: Applied Hydrology, Ven Te Chow)

Jika hidrograf aliran yang terjadi pada suatu DAS melebihi dari bankfull discharge, maka volume selisih antaranya merupakan volume limpasan yang terjadi. Volume limpasan tersebut merupakan kontribusi banjir pada suatu DAS.

\subsection{Aliran Permanen (Steady Flow)}

Aliran permanen (steady flow) merupakan kondisi untuk menghitung profil muka air aliran permanen berubah beraturan (steady gradually varied flow). Aliran yang dapat dilakukan pemodelan adalah aliran yang berupa aliran subkritis, superkritis, maupun kritis. Langkah hitungan profil muka air yang dilakukan aliran permanen (steady flow) didasarkan pada penyelesaian persamaan energi (1-Dimensi). Kehilangan energi dianggap diakibatkan oleh gesekan (Persamaan Manning) dan kontraksi/ekspansi (koefisien dikalikan beda tinggi kecepatan).

Pada kondisi aliran permanen, Pemodelan aliran menghitung profil muka air disepanjang alur sungai yang diurut dari satu cross section ke cross section berikutnya. Profil muka air ditentukan dengan menggunakan persamaan energi yang diselesaikan dengan metode standard step method. Persamaan energi antara dua tampang lintang dituliskan dalam bentuk persamaan berikut:

$$
Y_{2}+Z_{2}+\frac{\alpha_{2} V_{2}^{2}}{2 g}=Y_{1}+Z_{1}+\frac{\alpha_{1} V_{1}^{2}}{2 g}+h_{e}
$$

dengan keterangan:

$$
\begin{array}{ll}
\mathrm{Y}_{1}, \mathrm{Y}_{2} & =\text { kedalaman aliran } \\
\mathrm{Z}_{1}, \mathrm{Z}_{2} & =\text { elevasi dasar saluran } \\
\mathrm{V}_{1}, \mathrm{~V}_{2} & =\text { kecepatan rata-rata }(\mathrm{Q} / \mathrm{A}) \\
\mathrm{a}_{1}, \mathrm{a}_{2} & =\text { koefisien } \\
\mathrm{hl} & =\text { kehilangan tinggi energi }
\end{array}
$$

Gambar berikut merupakan ilustrasi dari profil suatu aliran berubah beraturan berdasarkan persamaan energi

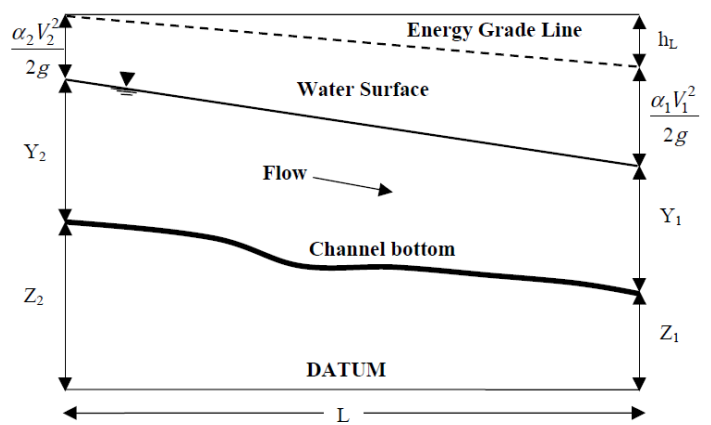

Gambar 3. Profil aliran berubah beraturan (Sumber: Applied Hydrology, Ven Te Chow)

\subsection{Aliran Tidak Permanen (Unsteady Flow)}

Aliran tak permanen (Unsteady Flow) dapat mensimulasikan aliran tak permanen dengan pemodelan 1 dimensi pada sungai yang memiliki alur yang lengkap. Pada kondisi aliran ini dapat dilakukan simulasi pada kondisi aliran subkritis, kritis dan superkritis. Aliran tak permanen (unsteady flow) merupakan kondisi aliran apabila kecepatan, kedalaman, dan debit aliran tidak berubah terhadap waktu. Pada aliran tak permanen merupakan proses fisik pada aliran di suatu saluran dengan mengadopsi konsep kekekalan massa dan kekekalan momentum. Proses fisik ini dapat digambarkan dengan persamaan matematis, yang dikenal sebagai Persamaan St. Venant. Persamaan tersebut terdiri dari persamaan kontinuitas (prinsip konservasi massa) dan persamaan momentum (prinsip konservasi momentum), yang dituliskan dalam bentuk persamaan diferensial parsial sebagai berikut:

$$
\frac{\partial A}{\partial t}+\frac{\partial Q}{\partial x}-q_{l}=0
$$

Persamaan Momentum

$$
\frac{\partial Q}{\partial t}+\frac{\partial Q V}{\partial x}+g A\left(\frac{\partial z}{\partial x}+S_{f}\right)=0
$$

dengan keterangan:

$\mathrm{A}=$ luas total tampang aliran

$\mathrm{Q}=$ debit aliran

$\mathrm{ql}=$ debit lateral per satuan panjang

$\mathrm{V}=$ kecepatan aliran 
$\mathrm{g}=$ percepatan grafitasi

$\mathrm{x}=$ jarak, diukur searah aliran

$\mathrm{z}=$ elevasi muka air

$\mathrm{t}=$ waktu

$\mathrm{Sf}=$ kemiringan garis energi (friction slope),

Dihitung dengan persamaan manning

$$
S f=\frac{n^{2}|Q| Q}{A^{2} R^{2}}
$$

$\mathrm{n}=$ koefisien kekasaran manning

$\mathrm{R}=$ radius hidraulik

Saluran dibagi menjadi tiga bagian, yaitu bantaran kiri, alur utama, dan bantaran kanan. Saat air sungai naik, air bergerak menyamping, menjauh dari alur utama, menggenangi bantaran dan mengisi tampungan-tampungan yang ada di sepanjang bantaran. Saat air mulai surut, air di bantaran bergerak menuju alur utama, menggantikan aliran di alur utama. Karena arah utama aliran adalah sepanjang alur utama, aliran dua dimensi ini sering dapat didekati dengan anggapan aliran satu dimensi.

\section{Metodologi}

\subsection{Data Daerah Studi}

DAS Citarum Hulu memanfaatkan teknologi penginderaan jauh untuk menyediakan informasi mengenai liputan lahan dengan interpretasi obyek yang ada pada citra.

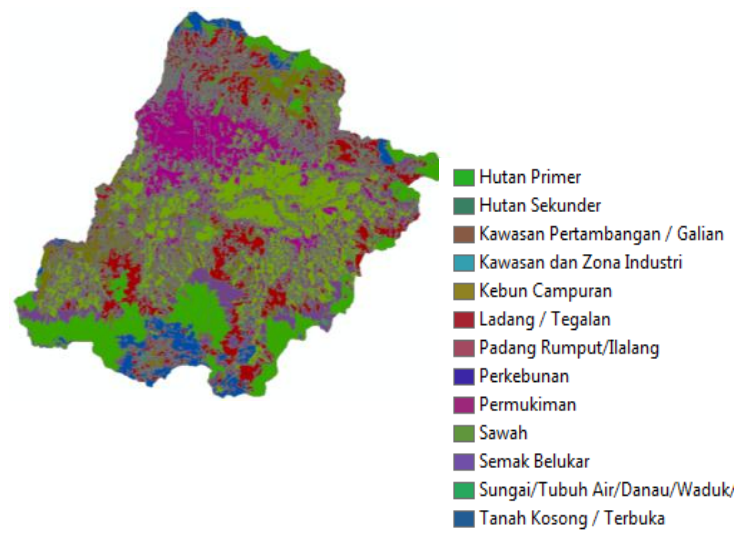

Gambar 4. Penggunaan lahan tahun 2010 DAS Citarum Hulu (Sumber: Hasil pengolahan sendiri berdasarkan data dari BBWS Citarum)

\subsection{Metodologi Penelitian}

Pemodelan banjir (flood modeling) merupakan suatu metode dalam memprediksi banjir pada suatu DAS. Metode yang digunakan bergantung pada ketersediaan data dan kesesuaian suatu metode dengan karakteristik daerah studi. Metodologi pada analisis hidrograf banjir terdiri dari dua bagian yaitu tahap pertama analisis curah hujan, dan tahap berikutnya analisis kalibrasi dan verifikasi untuk mendapatkan hidrograf satuan sintetis yang sesuai dengan DAS Citarum Hulu.

Pemodelan hidraulik dilakukan dengan bantuan software HEC-RAS 5.03. Pada pemodelan ini yang dijadikan input ada lima hal yaitu: data long section dan cross section Sungai Citarum Hulu, nilai awal (initial condition), syarat batas (boundary condition), koefisien manning, slope. Hasil channel routing pada stasiun pengukuran debit sebagai outlet yaitu Sta. Dayeuh Kolot akan dibandingkan dengan debit observasi pada stasiun tersebut. Model yang sudah ada ditentukan terlebih dahulu bankfull capacity dari Sungai Citarum Hulu. Penelusuran dengan bantuan software HEC-RAS 5.03. kemudian akan dibandingkan hidrograf hasil penelusuran pada outlet Stasiun Dayeuh Kolot. Pemodelan banjir tersebut dilakukan untuk pemodelan 1-D (one dimensional modelling) dan pemodelan 2-D (two dimensional modelling). Kedua metode pemodelan tersebut) kemudian dikomparasikan dengan debit observasi, dan kemudian dianalisis paameter-parameter yang mempengaruhi hasil pemodelan tersebut. Hasil komparasi kemudian ditentukan kekuatan dalam memprediksi pemodelan dengan metode Nash-Sutcliffe model efficiensy coefficient (E).

$$
E=1-\frac{\sum_{t=1}^{T}\left(Q_{o}^{t}-Q_{m}^{t}\right)^{2}}{\sum_{t=1}^{T}\left(Q_{o}^{t}-\overline{Q_{o}}\right)^{2}}
$$

dimana: $Q_{o}$ adalah debit observasi, $Q_{m}$ adalah debit pemodelan dan $Q_{m}{ }^{t}$ adalah debit observasi pada waktu $t$. Jika nilai indeks $E=1$ artinya pemodelan mendekati sempurna antara debit pemodelan dengan debit observasi, untuk nilai indeks $\mathrm{E}=0$ artinya prediksi model sama akuratnya dengan nilai rata-rata debit ibservasi, sedangkan jika nilai indeks $\mathrm{E}<0$ artinya ratarata debit observasi prediksinya lebih baik dari pada model tersebut.

\section{Hasil dan Pembahasan}

Secara garis besar hasil pemodelan banjir terdiri dari dua bagian yaitu Pemodelan 1-D (One Dimensional Modelling) dan Pemodelan 2-D (Two Dimensional Modelling) dengan bantuan Software HEC-RAS 5.03.

\subsection{Hasil Pemodelan 1-D (One Dimensional Modelling)}

Pemodelan 1-D menggunakan software HECRAS 5.03 kondisi unsteady flow menggunakan input data berupa penampang memanjang 


\section{Studi Komparasi Pemodelan 1-D (Satu Dimensi) Dan 2-D (Dua Dimensi) Dalam Memodelkan Banjir Das Citarum Hulu}

(long section) dan penampang melintang (cross section), data syarat batas (boundary condition) di hulu dan hilir, data kemiringan dasar saluran dan koefisien manning. Gambar berikut merupakan hasil pemodelan 1-D DAS Citarum Hulu.

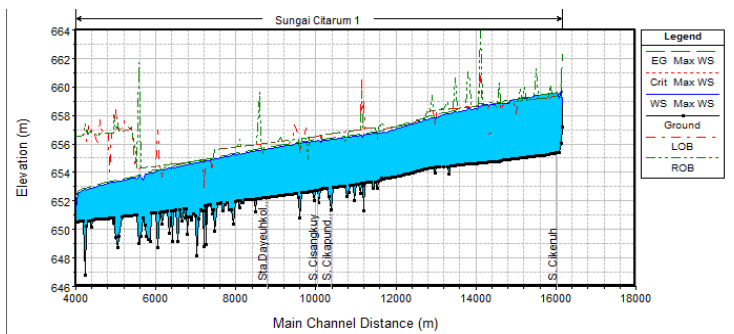

(a)

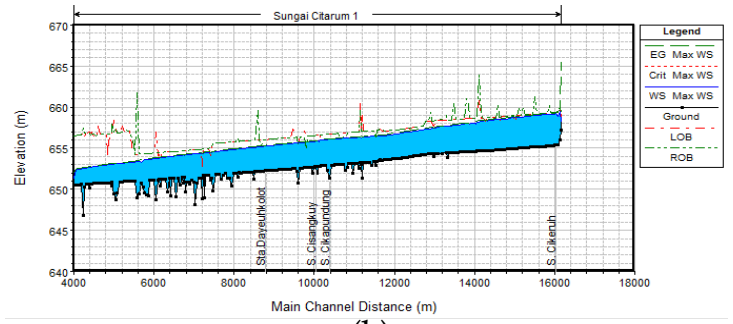

(b)

Gambar 5. Hasil pemodelan 1-D pada DAS Citarum Hulu periode ulang 25 tahun: (a) tahun 2007; (b) tahun 2008.

\subsection{Hasil Pemodelan 2-D (Two Dimensional Modelling)}

Pemodelan 2-D menggunakan software HECRAS 5.03 untuk kondisi unsteady flow menggunakan input data berupa penampang memanjang (long section) dan penampang melintang (cross section), data syarat batas (boundary condition) di hulu dan hilir, data kemiringan dasar saluran, koefisien manning dan data DEM (Digital Elevation Model) untuk menggambarkan kondisi topografi DAS Citarum Hulu.

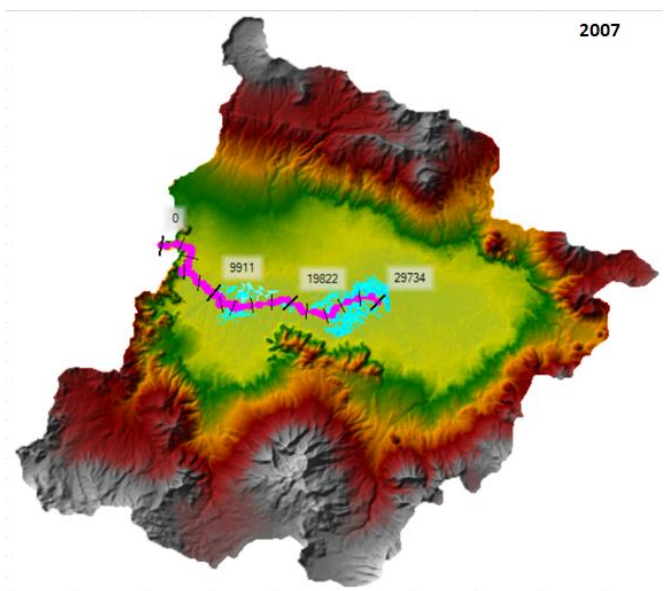

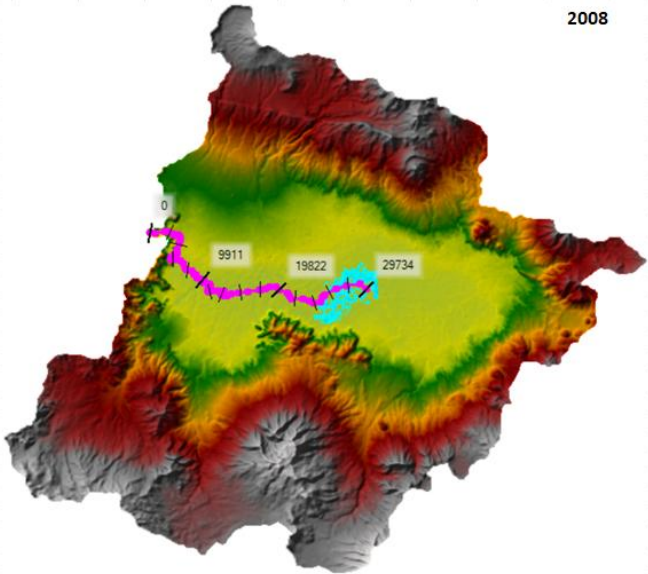

Gambar 6. Hasil pemodelan 2-D pada DAS Citarum Hulu periode ulang 25 tahun

Pada syarat batas menggunakan hidrograf banjir hasil analisis dengan menggunakan HEC-HMS untuk periode ulang 25 tahun untuk beberapa event banjir tahun 2007 dan 2008. Gambar berikut merupakan hasil pemodelan 2D DAS Citarum Hulu. Gambar di atas bahwa analisis pemodelna 2-D dengan data DEM menghasilkan dbit banjir dan genangan akibat luapan sungainya (terlihat pada dari bagian yang berwarna biru).

\subsection{Kalibrasi dan Verifikasi}

Hidrograf satuan sintetis SCS dan Snyder yang diperoleh berdasarkan parameter yang menjadi input sub DAS pada DAS Citarum Hulu, dengan bantuan software HEC-HMS versi 3.5 maka dilakukan analisis kalibrasi dan verifikasi. Hujan yang terjadi merupakan hujan total harian yang dianggap terdistribusi secara merata pada sub DAS.

Pada proses kalibrasi dan verifikasi berdasarkan debit observasi masing-masing sub DAS yang sudah dipisahkan dari baseflow dengan menggunakan straight line method sehingga yang dikalibasi dan diverifikasi merupakan direct runoff untuk tahun 2007 dan 2008 data debit yang tersedia. Sehingga diperoleh nilai Nash Index untuk tahun 2007 sebesar 0.74 dan tahun 2008 sebesar 0.71, artinya kedua nilai tersebut mendekati sama dengan 1 dan pemodelan dapat diterima.

\subsection{Analisis Pemodelan}

Berdasarkan hasil pemodelan 1-D dan 2-D menggunakan software HEC-RAS 5.03 diperoleh debit banjir dari masing-masing event banjir tahun 2007 dan 2008 sebagai berikut. 


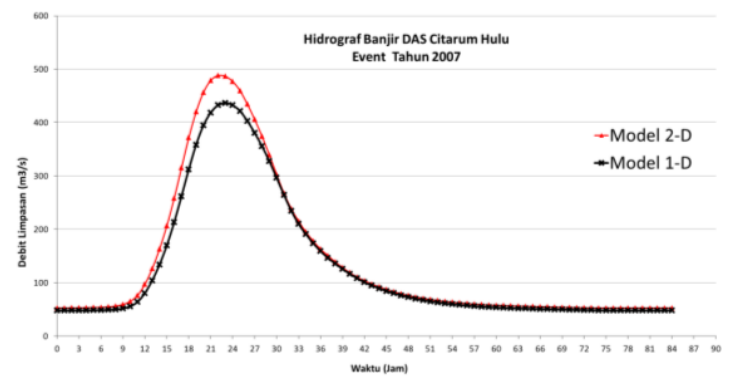

Gambar 7. Hasil pemodelan 1-D dan model 2-D pada DAS Citarum Hulu periode ulang 25 tahun untuk event banjir tahun 2007

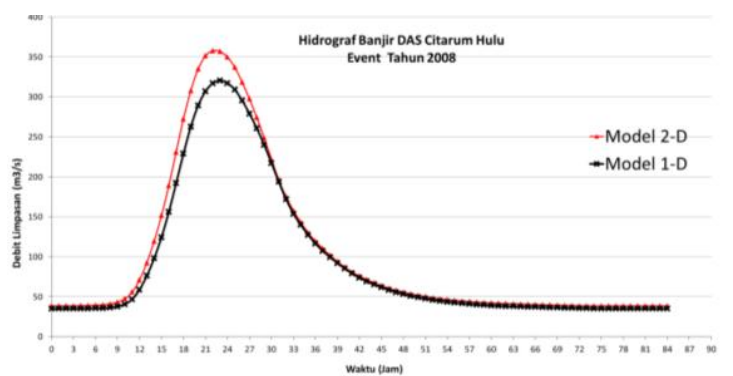

Gambar 8. Hasil pemodelan 1-D dan model 2-D pada DAS Citarum Hulu periode ulang 25 tahun untuk event banjir tahun 2008

Hidrograf banjir tersebut dengan kedua metode pemodelan 1-D dan 2-D kemudian dikomparasikan. Tingkat perbandingan tersebut dianalisis dengan Nash Index sehingga menghasilkan nilai terkait debit yang dihasilkan dari kedua pemodelan tersebut. Berdasarkan metode Nash Index (Indeks E) diperoleh hasil seperti tabel berikut.

Tabel 1. Hasil komparasi pemodelan hidrologi dengan pemodelan hidrolika

\begin{tabular}{ccc}
\hline No. & $\begin{array}{c}\text { Nama } \\
\text { Event }\end{array}$ & $\begin{array}{c}\text { Nilai Nash Index } \\
\text { E (NI) }\end{array}$ \\
\hline 1 & Event 2007 & 0.64 \\
\hline 2 & Event 2008 & 0.62 \\
\hline & Rata-rata & 0.63 \\
\hline
\end{tabular}

Tabel tersebut menunjukan bahwa pemodelan 1-D dan pemodelan 2-D jika dibandingkan dengan memiliki nilai mendekati satu, artinya hasil pemodelan tersebut tidak memiliki perbedaan jauh. Sehingga pemilihan analisis pemodelan dengan 1-D dan 2-D dapat dilakukan tergantung ketersediaan data dan tidak berpengaruh jauh terhadap hasil yang akan diperoleh dari pemodelan tersebut.

\section{Simpulan}

Komparasi antara model 1-D dengan model 2-D menggunakan software HEC-RAS 5.0.3 merupakan hasil dari respon curah hujan sebagai parameter utama pembentukan model. Model 1-d dan 2-D yang dibuat setelah dilakukan kalibrasi dan verifikasi sebelumnya dapat digunakan untuk besarnya hujan tertentu untuk memprediksi banjir. Selain dari curah hujan, tata guna lahan yang digunakan merupakan parameter penting yang dianalisis dalam pembentukan model. Time of concentration sebagai input pemodelan juga mempengaruhi hasil model tersebut. pemodelan 1-D dan pemodelan 2-D jika dibandingkan dengan memiliki nilai mendekati satu, artinya hasil pemodelan tersebut tidak memiliki perbedaan jauh. Sehingga pemilihan analisis pemodelan dengan 1-D dan 2-D dapat dilakukan tergantung ketersediaan data dan tidak berpengaruh jauh terhadap hasil yang akan diperoleh dari pemodelan tersebut.

\section{Daftar Pustaka}

Amir, Khan, Rasul, Sharma, and Akram, (2014). Watershed Delineation and CrossSection Extraction from DEM for Flood Modeling, 19th Australasian Fluid Mechanics Conference, Melbourne, Australia.

Arturo Leon, (2013). Tutorial on Using HECGeo RAS 10.1 with Arc GIS 10.1 and HEC-RAS 4.1.0 for Flood Inundation Mapping in Steady and Unsteady Flow Conditions, School of Civil and Construction Engineering, Oregon State University.

Gichamo, T.Z., Popescu, Jonoski, Solomatine. (2011). River Cross-Section Extraction from The ASTER Global DEM for Flood Modeling, Elsevier.

Grimaldi, Salvatore, etl. (2013). "Flood Mapping in Ungauged Basins Using Fully Continuous HydrologicHydraulic Modeling.". Journal of Hydrology, Elsevier, 487, 39-47 


\section{Studi Komparasi Pemodelan 1-D (Satu Dimensi) Dan 2-D (Dua Dimensi) \\ Dalam Memodelkan Banjir Das Citarum Hulu}

Jantzen, Tyler L, etl (2015). “Use of Flood Modeller Pro to Develop Linked, Alternating 1-D and 2-D Models of Overland and in-River Flows for Breach of a Large Off-Channel Ring Dam". The 32nd Annual Conference of The Association of State Dam Safety Officials, New Orlens, Louisiana.

Natalia Kolecka, Jacek Kozak. (2012). Assessment of the Accuracy of SRTM C-and X-Band High Mountain Elevation Data: a Case Study of the Polish Tatra Mountains, Pure and Applied Geophysics, Vol. 171, Krakow, Poland, 2014.Chidungdoan, Anhtuandao, Shie-Yui Liong, Richard Sanders, Jiandong Liu, and Timothy Fewtrell, Investigation of Possible Usage of SRTM for Ciliwung River Modeling, 10th International Conference on Hydroinformatics, Hamburg, Germany.

Paiva, Rodrigo, etl. (2013). "Validation of a Full Hydrodynamic Model For LargeScale Hydrologic Modeling in The Amazon.". Hydrological Processes, 27 (3), 333-346.

Kiesel, Jens, etl. (2013). "Application of a Hydrological-Hydraulic Modeling Cascade in Lowlands for Investigating Water and Sediment Fluxes in Catchment, Channel and Reach.". Journal of Hydrology and Hydromechanics, 61 (4), 334-346.

US ARMY Corps of Engineers. (2010). HECRAS River Analysis System: User's Manual. US Army Corps of Engineers, Washington.

Tarpanelli, A., etl. (2013). "Hydraulic Modeling Calibration in Small Rivers by Using Coarse Resolution Synthetic Aperture Radar Imagery.". Hydrological Processes, 27 (9), 1321-1330.

Venkatesh Merwade, (2012). Tutorial on Using HEC-Geo RAS with Arc GIS 10 and HEC-RAS Modeling, School of Civil Engineering, Purdue University.

Weish, Wendy D., etl. (2013). “An Integrated Modeling Framework for Regulated River Systems.". Environmental Modeling \& Software, Elsevier, 39, 81102.
Wen, Li., etl. (2013). "From Hydrodynamic to Hydrological Modeling: Investigating Long-Term Hydrological Regimes of Key Wetlands in The Macquarie Marshes, a Semi-Arid Lowland Floodplain in Australia.". Journal Hydrology, Elsevier, 500, 45-61.

Rohmat, Dede. (2009). Solusi Aspiratif Penanganan Masalah Sungai Mati (Kasus: Desa Andir Kecamatan Baleendah Kabupaten Bandung). Dimuat pada Jurnal GEA.

Sjafruddin, Ade. (2012). Bahan Kuliah Studi Kelayakan dan Pendanaan Infrastruktur. Teknik Sipil - ITB.

Soekartawi. (1995). Dasar Penyusunan Evaluasi Proyek. Jakarta : Pustaka Sinar Harapan.

Sosrodarsono, Suyono, Masateru Tominaga. (1994). Perbaikan dan Pengaturan Sungai. Jakarta: PT. Pradnya Paramita.

Suyatno, Adi.,Trie M. Sunaryo., Roestam Syarief. (2003). Ekonomi Teknik Proyek Sumber Daya Air. Jakarta: PT. Medisa.

Tang, Siu Lam. (1991). Economic Feasibility of Project. McGraw-Hill Book Singapore. 